\title{
Bolívia em disputa: das comunidades andinas à Revolução de 1952
}

\author{
Davi Antunes da Luz ${ }^{1}$ \\ https://orcid.org/0000-0001-6565-4257 \\ Lucas Lima da Silva ${ }^{2}$ \\ https://orcid.org/0000-0001-6267-0382

\begin{abstract}
${ }^{1}$ Universidade Federal de Santa Catarina, Departamento de Serviço Social, Programa de Pós-Graduação em Serviço Social, Florianópolis, SC, Brasil

${ }^{2}$ Universidade Federal de Santa Catarina, Departamento de Economia e Relações Internacionais, Curso de Relações Internacionais, Florianópolis, SC, Brasil
\end{abstract}

\section{Bolívia em disputa: das comunidades andinas à Revolução de 1952}

Resumo: A formação econômico-social latino-americana é marcada historicamente pelo processo de expropriação dos meios de trabalho na acumulação primitiva de capital europeu, separando os povos de suas terras e formas de organização comunitárias e conformando uma estrutura de dependência dos países da América Latina. A Bolívia passa por esse processo de disputa da terra desde sua fundação e é transformada pelas lutas sociais derivadas dessas contradições, síntese deste conflito foi a Revolução de 1952. Assim, é perceptível uma captura das tentativas autônomas e revolucionárias de resolução dos conflitos da terra pelo Estado, submetendo-as à lógica do capital, de tal forma que mais deformidades econômicas, sociais e geográficas são desdobradas no território boliviano, com conflitos de classe permeados de regionalismo. Esta pesquisa deu-se em caráter qualitativo, por meio do método do materialismo histórico-dialético, com uma revisão teórica e histórica.

Palavras-chave: Bolívia. Terra. Comunidade. Capital. Reforma Agrária.

\section{Bolivia in dispute: from the andean communities to the 1952 Revolution}

Abstract: The economic and social formation of Latin America is historically marked by the process of expropriation of the means of labor in the primitive accumulation of European capital, separating people from their lands and forms of community organization and forming a structure of dependence on Latin American countries. Bolivia has gone through this process of land dispute since its foundation and is transformed by social struggles arising from these contradictions, the synthesis of this conflict was the Revolution of 1952. Thus, it is noticeable a capture of the autonomous and revolutionary attempts to resolve land conflicts by the State, submitting them to the logic of capital, in such a way that more economic, social and geographic deformities are unfolded in the Bolivian territory, with class conflicts permeated by regionalism. This research was carried out in a qualitative way, through the method of historical-dialectical materialism, with a theoretical and historical review.

Keywords: Bolivia. Earth. Community. Capital. Land reform

Recebido em 02.03.2021. Aprovado em 15.05.2021. Revisado em 19.07.2021.

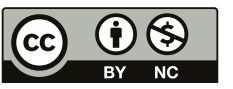

Este é um artigo publicado em acesso aberto (Open Access) sob a licença Creative Commons Attribution NonCommercial, que permite uso, distribuição e reprodução em qualquer meio, sem restrições desde que sem fins comerciais e que o trabalho original seja corretamente citado. 


\section{Introdução}

Para compreender a Bolívia, precisa-se entender necessariamente a história de dois modos de produção: o comunal e o do capital. Antes da chegada europeia, que traria consigo a inserção do modelo mercantil-capitalista, o modelo predominante visto de norte a sul do continente latino-americano era o da vivência comunal familiar. Nos Andes, região de difícil cultivo e manejo de seus recursos naturais, dos cumes montanhosos à costa do Oceano Pacífico, do altiplano até a floresta amazônica, floresceram milhares de comunidades. Durante séculos estes grupos iriam se aperfeiçoar quanto ao domínio do meio e seu cultivo, crescendo não só em territórios, mas também complexificando suas relações intercomunais; sendo, inclusive, cenário do maior mando já visto até então nas Américas: os incas.

Porém, com o início da invasão colonial no século XV, essa lógica comunitária rapidamente seria colocada em risco. Através de violentas investidas, a sede europeia por metais faria do Alto Peru — que viria a se tornar a Bolívia - um dos principais veios econômicos cujo destino seriam as metrópoles europeias. Por meio da anexação das comunidades andinas pelos vice-reinados espanhóis ocorreria a deturpação de suas virtudes e características originais com a escravização de sua mão de obra.

Em 1825, com a independência da Bolívia, quando se têm rompidos os laços administrativos coloniais e se adentra o quadro de dependência, o indígena é colocado às margens do Estado enquanto suas comunidades são despojadas de seu caráter coletivista de produção. Há um esvaziamento da unidade social, antes reconhecida na terra, que começa a ser retomada em duras lutas centradas no trabalho no decorrer do século XX, culminando no processo revolucionário de 1952, no qual trabalho e terra buscam criar coesão produtiva entre os territórios bolivianos.

Assim, no presente trabalho temos como objetivo evidenciar, por meio de revisão histórica e teórica, as contradições entre o modo de produção comunal e o capitalista, reconhecendo que o primeiro nunca é anexado por completo pelo segundo, resultando em uma condição específica de antagonismos sociais que estruturam a sociedade boliviana. O texto é organizado em três seções. Na primeira, trabalhamos a discussão sobre a acumulação primitiva e a dependência, atentando para a relação entre Estado e terra. Na segunda, abordamos o elemento comunitário desde o período pré-incaico até a primeira metade do século XX, destacando momentos históricos fundamentais para o entendimento da questão. Por fim, na terceira seção buscamos evidenciar a disputa pela terra e pelo território, e suas consequências políticas durante a República, marcadamente a Revolução de 1952 e o processo de reforma agrária de 1953.

\section{Terra e capital: a assim chamada acumulação primitiva do lado de cá}

Para compreender a formação do capitalismo, como estrutura histórica organizadora da produção e reprodução da vida no campo econômico e social, tanto em escala mundial quanto nacional, é fundamental analisar as transformações que ele realiza nos territórios. A universalidade das leis econômicas se manifesta concretamente nas particularidades regionais, em que as relações e as lutas sociais se desdobram, e o tempo se encontra com o espaço.

Em seus germes de formação, o capitalismo condicionou sucessivos processos de cisão por onde passou, objetivos e subjetivos, sendo o mais primitivo apontado por Marx n'O Capital:

[...] o processo de separação entre o trabalhador e a propriedade das condições de realização de seu trabalho, processo que, por um lado, transforma em capital os meios sociais de subsistência e de produção e, por outro, converte os produtores diretos em trabalhadores assalariados. A assim chamada acumulação primitiva não é, por conseguinte, mais do que o processo histórico de separação entre produtor e meio de produção (MARX, 2017, p. 786).

Ao separar os trabalhadores de suas condições e meios de produção, nos quais reconheciam sua existência, força-se com severa violência a imensos contingentes de pessoas a alienação de suas formas de vida e relação com seus territórios. A acumulação primitiva é base condicionante do desenvolvimento capitalista, na medida em que subordina o conjunto da existência social ao capital através de suas expropriações. 
Quando Marx (2017, p. 787) coloca que "A expropriação da terra que antes pertencia ao produtor rural, ao camponês, constitui a base de todo o processo", deve-se atentar que a expropriação é antes uma alteração no regime de propriedade, sendo o fator desencadeador da mudança nas relações sociais. Destas novas relações sociais surge todo um arcabouço jurídico-político, submetendo a população rural ao sistema de assalariamento, por meio de leis grotescas, força de açoites, ferros em brasa e torturas (MARX, 2017).

Esta é a forma assumida no processo capitalista na Europa, mais especificamente na Europa ocidental. Contudo, Marx reconhece nos processos coloniais que adentraram o Novo Mundo também a sua face expropriadora, em que

a descoberta das terras auríferas e argentíferas na América, o extermínio, a escravização e o soterramento da população nativa nas minas, o começo da conquista e saqueio das Índias Orientais e a transformação da África numa reserva para a caça comercial de peles-negras caracterizam a aurora da produção capitalista (MARX, 2017, p. 821).

Na América Latina, se os europeus consideravam a colonização um Novo Mundo, para os povos que aqui habitavam foi o início do fim. O empreendimento colonial mudou drasticamente a sociabilidade dos povos originários, do interior do México até a ponta do Ushuaia, por arrancá-los de sua vinculação com a terra. Vale destacar que a relação indígena com a terra assume um caráter holístico espiritual do qual o aspecto econômico era somente uma parte, ligado ao sistema de crenças e valores representados por inúmeras divindades em uma complexa cosmogonia. Nos seus estudos tardios sobre sociedades pré-capitalistas, Marx reconhece que as "formas comunais mais antigas talvez não fossem revolucionárias em si mesmas, mas poderiam se tornar um 'perigo' para a ordem social ao colidirem com a modernidade capitalista" (ANDERSON, 2015, p. 314-323), e por isso houve uma ligação, por parte da burguesia europeia, da "propriedade comunal indígena e do movimento socialista contemporâneo, à medida que ambos eram obstáculos para o estabelecimento das relações de propriedade burguesas".

José Carlos Mariátegui, um dos maiores intelectuais latino-americanos do século XX, mesmo não tendo tido contato com esses escritos tardios, ao seguir o mesmo método de Marx, chega às mesmas conclusões e vai além ao tratar a questão indígena e da terra em conjunto e de forma indissociada. Para o peruano, a desgraça dos povos indígenas foi a conquista espanhola ter destruído seu passado sem poder construir algo novo em seu lugar, pois o "regime colonial desorganizou e aniquilou a economia agrária incaica, sem substituí-la por uma economia de rendimentos superiores" (MARIÁTEGUI, 2010, p. 72).

Mariátegui, ao tratar da terra e do indígena, dá um salto interpretativo quando descola os aspectos morais, éticos e religiosos da miséria indígena e a trata como fruto da economia, assentando raízes na propriedade da terra, na destruição do ayllu'. Então, o "novo exame do problema indígena, por isso, se preocupa muito menos com as linhas gerais da legislação tutelar que com as consequências do regime da propriedade agrária." (MARIÁTEGUI, 2010, p. 55).

Ao expropriarem esses indígenas de suas terras para a consolidação dos latifúndios monocultores ligados ao capital comercial europeu (ibérico e, posteriormente, britânico), foi possível instaurar diversas formas de trabalho por servidão indígena - como foi visto na América hispanohablante através da encomienda, mita, enganche e yanaconagem - para a extração de prata e estanho na Bolívia ou guano e salitre no Peru. A colonização é o ponto de partida da questão agrária latino-americana, em que o núcleo colonial da "fazenda, monopolizando, com a terra e as indústrias conexas, o comércio e os transportes, priva o vilarejo de meios de vida e o condena a uma existência sórdida e exígua" (MARIÁTEGUI, 2010, p. 49).

Na constituição dos Estados latino-americanos, após seus processos de independência, os "privilégios da colônia tinham engendrado os privilégios da república" (MARIÁTEGUI, 2010, p. 88), assegurando o poder do latifúndio no manejo do capital comercial. Esses privilégios conformam novos padrões de produção e dominação política, criando um conjunto de deformações em nossas sociedades, entendidas como "uma acentuação muito marcada da lei do desenvolvimento desigual do capitalismo, que chega a configurar verdadeiros pontos de 'atrofia' e 'hipertrofia' simultâneas no aparato produtivo latino-americano" (CUEVA, 1979, p. 32, tradução nossa). Pela economia voltada para o exterior, há uma hipertrofia das costas exportadoras e uma expropriação concentradora e centralizadora no interior, atrofiando o mercado interno na medida em que havia pouco assalariamento, muita servidão e formas agudas de exploração, via de inserção latino-americana no capitalismo moderno, em que 
as relações de exploração podem se apresentar mais nitidamente como relações servis, sem que isso impeça que, através da extorsão do mais-produto do trabalhador pela ação do capital comercial ou usurário, o trabalhador se veja implicado em uma exploração direta pelo capital, que tende inclusive a assumir um caráter de superexploração (MARINI, 2010, p. 153).

Essa inserção se dá em bases muito concretas, formadoras tanto das relações sociais produtivas quanto do Estado, e só pode ser compreendida dentro da categoria analítico-explicativa da dependência, entendida como uma situação em que os países latino-americanos têm suas economias condicionadas pelo desenvolvimento e expansão de outra economia à qual se encontram submetidas, determinando limites e possibilidades para estes países e seus povos (DOS SANTOS, 1970 apud BAMBIRRA, 2015). Essa chave analítica é a que explica as condições e as deformidades do subdesenvolvimento das nossas formações sociais, tornando-as "incapazes de superá-las através do simples funcionamento do sistema, porque a própria prosperidade, ao reforçar o vínculo externo de dependência, se torna fator de atraso" (RIBEIRO, 1978, p. 21).

$\mathrm{O}$ vínculo da dependência se insere dentro dos processos industriais e das inovações das forças produtivas e amplia-se dentro das modificações do capitalismo em sua etapa imperialista, com todas as suas características de concorrência exacerbada, centralização e concentração monopólica do capital e da produção e militarismo anexionista de territórios em mercados e povos e trabalhadores expropriados. Estas realidades são o centro da dinâmica social e causam a

[...] alteração da base morfológica e ecológica da sociedade, passando pela geração de novas necessidades, até a desagregação das formas econômicas e sociais anteriores e o surgimento de novas classes por ela gerado, o que provoca variações no eixo das contradições e nos conflitos da sociedade (BAMBIRRA, 2015, p. 61-62).

O Estado que surge nesta realidade dependente no conjunto da economia imperialista assume diversas formas políticas - oligárquica, populista, democrática liberal, ditatorial — para garantir interesses de classe, dispondo de força e consenso. Em sentido gramsciano, a sociedade política (Estado) exerce a dominação direta, fundada juridicamente, enquanto a sociedade civil exerce a função de organização "de visões de mundo, da consciência social, de formas de ser adequadas aos interesses do mundo burguês [...]" (FONTES, 2010, p. 133).

Esse panorama histórico conceitual serve para alicerçar a análise do processo boliviano de transformação histórica do regime de propriedade, em específico da propriedade indígena, e suas consequências atuais que mobilizam formas de resistência à destruição da relação dos povos com seus territórios.

\section{Terra e território na Bolívia: comunidade, colônia e Estado}

Desde tempos imemoriáveis, os povos andinos realizam sua história baseando-se no desenvolvimento de uma interação societária comunal. Ao longo dos séculos, do domínio incaico à colonização europeia, a cosmovivência indígena se realizou através da relação entre o indivíduo e a natureza onde, por meio do trabalho, a sua comunidade e o divino sobreviviam no convívio e pela terra.

Tal modo de produção possui um longo passado, com os primeiros povos nômades percorrendo a costa do Pacífico através da organização de clã — a forma mais simples de associação entre grupos familiares. Assim, conforme o domínio da terra se estendia, a apropriação e utilização coletiva do solo acabavam por proporcionar a fixação do grupo em um território. Atualizando, com o advento da agricultura, o senso de coletividade e foi alterando a forma como o ser humano relacionava-se com a terra, deixando esta de existir apenas como forma de sustento de recursos, através da caça e coleta, e passando a ser modificada objetivamente como meio de trabalho que requer intervenção e regulação para a realização de seus processos metabólicos e de produção (LINERA, 2009).

Como descreve Marx (2011, p. 389):

A terra é o grande laboratório, o arsenal, que fornece tanto o meio de trabalho quanto o material de trabalho, bem como a sede, a base da comunidade. Eles se relacionam com a terra, ingenuamente, como propriedade da comunidade, e da comunidade que se produz e reproduz pelo trabalho vivo. Somente como parte, como membro, desta comunidade, cada indivíduo singular se comporta como proprietário ou possuidor. 
A apropriação real pelo processo do trabalho se realiza sob esses pressupostos, que não são eles mesmos produto do trabalho, mas aparecem como seus pressupostos naturais ou divinos.

Nos Andes e em grande extensão da costa do pacífico, o modelo comunitário mais presente é o do ayllu, comunidades que, podendo abarcar diferentes pisos geográficos, reuniam-se em tempos pré-colombianos através de uma ordem familiar e comunal paternal (SAAVEDRA, 1998). Tal organização dá-se com o aspecto de que a socialização da produção e seu caráter coletivo são realizados com o objetivo de que produtores se relacionem aos demais membros da comunidade como coproprietários de um território comum do ayllu - a marka (BOLÍVIA, 2015).

A entidade comunitária surge assim como sujeito supremo sobreposto aos indivíduos que a compõem, tanto porque a ação de trabalhar para a vida é comunitária (no caso da comunidade arcaica) ou familiar (na comunidade agrícola), e também porque na valorização dos mais velhos da comunidade, dos ancestrais, no legado dos pais e da coesão comunitária vivida, manifesta a obtenção das condições de vida, alimentos, sementes, técnicas produtivas e terras para os novos produtores (LINERA, 2009, p. 282, tradução nossa).

Essa condição comunitária de autonomia interna e de estrutura como célula produtiva única se manteve em tempos pré-incaicos como o principal modelo de sociedade, tendo, durante séculos na região, casos em que grupos militares e religiosos acabaram por se espalhar, submetendo outras comunidades ao seu domínio, tal como foi com os wari e os tiahuanaco. Porém, nenhum movimento de dominação e anexação de milhares de comunidades seria tão forte quanto o dos incas, que durante seu movimento de conquista iriam formar o maior poderio já visto nas Américas: o Tawantinsuyu, o Incário.

Durante o domínio inca, que duraria pouco mais de trezentos e cinquenta anos, sua sociedade teria um lento começo, tendo por séculos se mantido próxima de Cusco, o centro de seu poder. Porém, em seus últimos noventa anos de existência, os incas iniciariam sua caminhada para além de sua capital, realizando seu expansionismo por quase toda a extensão dos Andes, e parando somente devido à chegada do Império espanhol em 1532. No tempo de suas conquistas, os governantes incas utilizavam-se da reciprocidade, um dos elementos fundantes da cosmovivência andina, como princípio em suas campanhas militares, tendo êxito em conseguir estender suas forças, no auge do Incário, desde o sul da Colômbia até metade do Chile, incorporando um enorme número de comunidades (ROSTWOROWSKI, 1999).

Todavia, longe de se manter como um único povo homogêneo, o Tawantinsuyu se encontrava dividido em quatro raias que por si possuíam suas próprias ramificações heterogêneas, separadas em milhares de grupos, com dezenas ou centenas de línguas e costumes diferentes. A união forçada através da reciprocidade no nível vertical das comunidades com a sociedade cusquenha se fazia frágil. De tal maneira, os conflitos eram constantes, com as comunidades mais distantes de Cusco, ou aquelas mais rebeldes, voltando-se constantemente contra o centro administrativo e seus representantes (ROSTWOROWSKI, 1999).

Dessa forma, para além da invasão europeia no continente latino-americano, a região dos Andes já sofria uma forte desintegração interna de sua força central com as comunidades, sendo, no entanto, elevada com os massacres promovidos pela Coroa espanhola. Porém, diferentemente de outras regiões como as ilhas do Caribe ou o Brasil, onde a organização originária indígena foi destruída após a escravização e o roubo de suas terras, na América hispânica da região andina e do Vice-Reino do Peru a mão de obra indígena seria escravizada e utilizada para trabalho nas minas de prata, como as de Potosí. Como descreve Souza (2020), seja com o trabalho negro ou indígena escravizado, perde-se o caráter comunitário e de associação de produtores em torno de um bem comum, a sobrevivência da comunidade e de seus elementos espirituais e naturais.

No escravismo colonial ele apresenta-se no seu reverso; de fundamento ontológico da humanidade, mecanismo que fez nascer o humano como humano ser social, ele se apresenta, diretamente, de deturpação das possibilidades criativas do sujeito, sua animalização e brutalização (SOUZA, 2020, p. 82-83).

Para além da extração da prata e de outros metais dos veios das montanhas e solos, o capital mercantilista não iria se instalar sobre um vácuo existencial anterior à sua presença. Utilizando-se dos indígenas nos campos e comunidades, a Coroa inicialmente empregaria um sistema de encomiendas - comunidades campesinas divididas em distritos onde seus habitantes deveriam realizar o pagamento de taxas a um supervisor - que, 
com a introdução da moeda no Alto Peru, serviria para gerar altos lucros para a metrópole com a produção rural e mineradora, enquanto milhares de indivíduos e comunidades, de diferentes origens étnicas, eram condensados em grupos menores (KLEIN, 2016).

Com o tempo, a encomienda deixaria de ser a principal forma de produção agrícola na colônia e em seu lugar, no Alto Peru, a mita, forma rotativa do trabalho originada nas comunidades indígenas desde tempos précolombianos, retornaria devido às reformas coloniais realizadas pelo vice-rei Francisco de Toledo. Contudo, esse retorno não poderia se afastar mais do princípio comunitário indígena, sendo a rotatividade agora realizada pelo regime de reducciones, onde comunidades de diferentes pisos ecológicos eram reduzidas em grupos menores e acabavam por trabalhar nas minas por exaustivos períodos; isto tornaria mais marcada a diferença, não só geográfica, entre o oriente - terras baixas - e o ocidente boliviano, com o primeiro mantendo-se como de maioria rural e indígena, enquanto o segundo seria o centro econômico e minerador com uma população de maioria mestiza - indivíduos de origem indígena e branca.

Após o auge minerador do século XVII, com a estabilização da população indígena após o primeiro choque colonial e a incorporação de trabalhadores mestizos nas minas, os veios de metal iriam se esgotar rapidamente causando um esvaziamento econômico e administrativo. Como resultado, ocorreu a anexação do Alto Peru ao novo Vice-Reino do Rio da Prata (atual Argentina), com a divisão do seu território em diversas intendências, de maneira que ocorreu o aumento dos indivíduos no campo e da concentração da terra em torno de grandes latifundiários, ao passo em que as propriedades comunais foram esvaziadas e o comércio através de Buenos Aires acabou predominando (KLEIN, 2016).

No entanto, as condições favoráveis à Coroa e administração interna seriam postas em xeque. Durante o século XVIII ocorreram as maiores rebeliões indígenas já vistas no continente, com milhões de indígenas e mestizos do Alto Peru se rebelando contra os corregedores da colônia em um movimento que, antes do seu violento fim com a morte e dispersão de suas lideranças, adquiriu o cunho independentista. Além do mais, em um quadro social que se manteve tenso durante décadas dentro da colônia, a metrópole agora enfrentava uma crise própria com o início das Guerras Napoleônicas, resultando no fechamento de rotas de comércio por toda a América (RAMOS, 2014).

Com a queda abismal da produção nas minas e do comércio, o Alto Peru teria de se manter cada vez mais através de sua agricultura, no entanto, devido a uma série de secas no altiplano e no vale, não só a produção de alimentos caiu, como também o nível de vida e o número total da população. Esse quadro social geraria então um movimento interno de conflito entre as elites criollas baixo-peruanas, portenhas e locais, grupos indígenas e as forças da metrópole, gerando uma cisão interna que levaria à formação de guerrilhas, inscritas dentro do quadro das investidas independentistas de Simón Bolívar pela América hispânica.

Desta forma, em 1825, a Bolívia se declararia independente, com o território do Estado abarcando em seus limites fronteiriços ao norte parte da floresta amazônica, ao oeste o Deserto do Atacama e percorrendo parte do Oceano Pacífico, ao leste fazendo fronteira com o Brasil e ao sul se estendendo por grande parte do Gran Chaco. Além do mais, Bolívar seria o primeiro presidente do país e o redator de sua primeira constituição. Porém, o presidente da Bolívia, que receberia também o nome do país em sua homenagem, logo seria deposto de seu cargo após sua constituinte desagradar as elites do país, que a caracterizaram como despótica, paternal e autoritária (RAMOS, 2014).

Com isso, a Bolívia logo passaria pela formação de uma nova constituição que teria semelhança com os ideais propostos por Bolívar - o Libertador ainda era um liberal convicto e não tinha a comunidade indígena bem entendida. Assim, com as elites moradoras e latifundiárias no poder, os ayllus seriam abolidos e, tal como qualquer outro modelo comunal, o papel dos kuraka ${ }^{2}$ seria destituído e substituído por funcionários do Estado, além do mais, seriam considerados cidadãos aqueles que não possuíam vínculos de servidão e que falassem o castelhano; ou seja, os indígenas, seus idiomas e sua classe seriam colocados fora do Estado boliviano (LINERA, 2010, p. 168-169).

Em consonância com esse fenômeno, desde sua independência até 1952, a Bolívia teria duas experiências de modelos de Estado, o primeiro caudilhista (1825-1880) e o segundo de uma democracia censitária (18801952), passando por períodos de anarquia, governo de alianças militares, juntas, representantes liberais e republicanos, somando mais de trinta presidentes e dezenas de alterações constitucionais (LINERA, 2010). Entre tais alterações estava a Ley de Exvinculación de 1874, considerada como a primeira experiência de 
reforma agrária boliviana, pois tinha como objetivo a modernização do campo e como elemento principal a destituição das comunidades e da formação de pequenas propriedades (PLATT, 2016).

O Estado boliviano passaria durante este período por uma série de conflitos internos, como a guerra civil boliviana do final do Século XIX, porém, as guerras fronteiriças com seus países vizinhos marcariam para sempre a história do país e os contornos de seu território. Tendo uma breve experiência unionista com o Peru, por meio da Confederação Peru-boliviana, entre 1836 e 1839, a Confederação seria desfeita como resultado da guerra com a Argentina, iniciada pela propensão peru-boliviana de anexar a província de Tarija, e que posteriormente envolveria o Chile e a parte norte do Peru que não havia sido integrada.

No entanto, ainda que o conflito gerado pela Confederação tenha causado perdas populacionais para a Bolívia, nada se compara aos impactos das três guerras enfrentadas pelo país entre 1879 e 1932: a Guerra do Pacífico, a Guerra do Acre e a Guerra do Chaco. Cada uma representaria não só uma perda substancial do território estatal boliviano - que ao final de 1932 encontrava-se reduzido à metade do território de 1825 —, como também a perda de sua saída para o mar, do Atacama, parte do norte amazônico e do Gran Chaco, e, além disso, significaria para os povos indígenas a desanexação territorial de parte de suas comunidades e terras originárias que se alongavam por uma vasta extensão de pisos geográficos (RAMOS, 2014).

Ademais, no século XIX e na primeira metade do século XX, ocorreria em dois momentos a emergência do proletariado mineiro e a alteração dos fundamentos da sociedade rural e urbana boliviana. A primeira fase realizada seria a do operário artesão de empresa, ou seja, o trabalhador de ofício que ainda se resignava a adentrar o ciclo industrial e mantinha-se próximo da estrutura produtiva comunal-camponesa de organização segmentada. A segunda fase seria a do operário de ofício de grande empresa, que apareceria juntamente ao auge da mineração do estanho e agora seria inserido no meio industrial e de utilização de maquinário não artesanal. Justamente deste elemento de vivência operária, advinda em boa parte da proeminência da preservação do coletivo radicado do indígena, que surgiu o espírito corporativo do sindicalismo boliviano, com a perpetuação da classe através da coesão existente entre o mestre de ofício e toda a sua cadeia de mandos - - algo que também recriou até a própria relação com os ancestrais e com uma liderança hierárquica dentro do vácuo gerado pelo esvaziamento das comunidades (LINERA, 2010, p. 118-119).

Com isso, os partidos políticos que conformam o cenário boliviano e se envolvem no processo revolucionário de 1952 são frutos de um amadurecimento político mais amplo das camadas populares bolivianas e de uma organização crescente da classe operária, contrastando diretamente com a degeneração institucional e das bases econômicas tradicionais do país nas décadas seguintes ao pós-guerra. Os grupos marxistas e socialistas da década de 1920 ganharam força e em 1935 aconteceu o Congresso que deu origem ao Partido Obrero Revolucionário (POR), influenciado pela crise da Guerra do Chaco (ANDRADE, 2007, p. 34) e que se tornou um dos grandes partidos da Quarta Internacional ${ }^{3}$. Com dissensões programáticas e organizativas, surgiram também outros partidos influenciados por setores da pequena burguesia, como o Partido de Izquierda Revolucionária (PIR) criado em 1940, originado de uma Frente de Esquerda forte no movimento estudantil ainda no ano anterior.

Os setores mais alinhados à burguesia se dividiram em dois, os situacionistas, representados pelo pacto da Concordância (Partido Liberal, Republicano Genuíno e Republicano Socialista) e os oposicionistas, representados pelo Movimiento Nacionalista Revolucionário (MNR) de Paz Estenssoro, que possuíam forte apelo popular, mas laços personalistas e práticas elitistas (ANDRADE, 2007, p. 40), forma de tomarem o centro do poder político após 1952.

\section{Um ponto de inflexão: a Revolução de 1952 e a reforma agrária de 1953}

O movimento operário boliviano, fortalecido pela organização sindical dos mineiros, tomava ano a ano maior caráter de massas, politizando a população sobre as questões fundamentais do país. Uma delas era a situação degradante no qual os mineiros trabalhavam para as mineradoras de Aramayo, Hochschild e Patiño ${ }^{4}$, onde a tentativa de reivindicar melhores condições de trabalho transformou minas em acampamentos militares. Em uma tênue fachada democrática com frágil estabilidade e muito autoritarismo, dois momentos colocaram mais pólvora para o estopim revolucionário de 1952.

O primeiro foi o Massacre de Siglo XX de maio de 1949, quando a queda do governo de Hertzog em um golpe de Estado ligado aos interesses mineiros colocou Mamerto Urriolagoitia na direção do país. A partir 
desse momento a fase conhecida como Sexênio (1946-1952) assumiu sua face ditatorial policialesca e, na tentativa de impor sua autoridade, reprimiu uma grande greve em Catavi, prendendo dirigentes e parlamentares operários e desarticulando a greve com balas que resultaram em uma onda de assassinatos.

O segundo momento foi a tentativa do governo de proibir a comemoração do $1^{\circ}$ de maio, dia do trabalhador, de 1950, o que desencadeou uma greve geral no país com um comitê dirigente dos partidos oposicionistas, maioria de esquerda, excetuando o MNR. A repressão estatal colocou tropas militares nas ruas e prendeu líderes populares, contudo houve resistência armada em La Paz, no bairro operário de Villa Victoria. O governo utilizou bombardeios aéreos para esmagar os revoltosos, deixando muitos mortos e o nível de violência em níveis extremos (ANDRADE, 2007, p. 64).

Foi nesse contexto que ocorreram as eleições de 1951 e a conformação de uma Junta Militar, havendo um fechamento do regime político boliviano dentro de um contexto recessivo de pagamento da dívida externa em uma estrutura econômica extremamente concentrada - no campo, $6 \%$ dos proprietários controlavam $92 \%$ das terras, das quais 1,5\% eram cultivadas (ANDRADE, 2007, p. 69). A oposição (POR, PIR, PCB e MNR) conformou uma frente ampla no mesmo ano com dois pontos programáticos: a democracia (e o reconhecimento das eleições de 1951) e a soberania nacional (sintetizada na nacionalização da mineração).

Nos primeiros meses de 1952 o MNR seguia com sua política de alianças golpistas em busca de tomar o poder sem mediação popular ou com os partidos de esquerda, enquanto a situação de repressão se agravava. Os dias 9, 10 e 11 de abril marcaram a tentativa de golpe e a irrupção popular, que começou com uma iniciativa de golpe "pelo alto" por parte do MNR e setores militares. A tentativa logo fracassou e pela seguinte ascensão e autonomia do movimento popular que adquiriu contornos revolucionários, colocando La Paz "sob o comando coletivo de milhares de homens e mulheres anônimos, revolucionários, invencíveis pelos regimentos mais equipados e preparados do Exército boliviano" (ANDRADE, 2007, p. 77). Em outros centros mineiros e campesinos, como Oruro e Ucureña, rapidamente a revolução se fortalecia e bases militares com seus armamentos eram tomadas.

Um novo governo formou-se com uma pactuação dos militares derrotados e dos dirigentes do MNR, sob a liderança de Paz Estenssoro, na tentativa de conter a mobilização popular e seu caráter de ruptura com a ordem. A partir desse momento duas políticas se confrontaram em todas as decisões políticas: a política revolucionária e independente das massas, coordenada a partir da recém fundada Confederación Obrera Boliviana (COB), e a política do governo do MNR, de ação institucional e desmobilizadora, tentando conter a radicalização popular.

Um exemplo dessa disputa está nos alicerces do movimento revolucionário, que, além dos dois pontos de democracia e soberania nacional, eram a reforma agrária e o direito à terra. A Revolução de 1952 foi, além de um movimento político profundo, um fator de mudança no grau e nos métodos de luta populares. A organização camponesa estava condicionada às formas de ocupação da terra - tipo de propriedade, formas de trabalho e níveis de relação com o mercado - mediadas pela questão étnica, onde as regiões de maioria indígena tinham maiores tensões entre a fazenda-comunidade (CUSICANQUI, 1985).

O grande impulso de formação sindical camponesa veio das transformações urbanas e ampliação da $\mathrm{COB}$, rompendo as divisões étnicas mais imediatas, mas mantendo as suas características comunitárias, o que os transformou em órgãos de autogestão local e poder popular, mesclando formas ancestrais de tomada de decisão coletiva com o sindicalismo urbano. Esses primeiros momentos foram de aplicação popular das promessas revolucionárias através das milícias armadas campesinas e pelos piqueros $^{5}$, apoiadas pelos trabalhadores urbanos.

Em 1953, formou-se a Comissão de Reforma Agrária, com membros do MNR, do POR e do PIR, e foi assassinado o decreto-lei $\mathrm{n}^{\circ} 3.464 \mathrm{em} 2$ de agosto em Ucureña, como forma do governo reformista do MNR acalmar os ânimos populares por meio de concessões. Desta comissão, dois foram os movimentos institucionais fundamentais de esvaziamento do conteúdo transformador que vinha do povo. O primeiro foi a burocratização da reforma agrária e a cooptação de suas lideranças, em que ocorreu uma instrumentalização política de um trâmite interminável ${ }^{6}$ que capturou tais sindicatos em sua forma corporativista vinculada ao governo. $\mathrm{O}$ segundo foi a intenção de esvaziar a indianidade e sua forma de ligação à terra, negando a vida comunitária no intento de tornar os indígenas em camponeses de minifúndio com lógica de mercado, dissolvendo a cosmogonia já citada neste texto, seus universos comunitários e seus valores tradicionais.

O resultado político foi um agravamento das deformações e disparidades regionais entre ocidente e oriente boliviano, processo que se desdobrou no decurso da segunda metade do século XX, intensificado com a ditadura de Paz Estenssoro em 1964. O ocidente boliviano (Ororu e Potosí) sofria de uma pressão demográfica grande e o parcelamento de suas terras, fruto da política minifundista de mercado e da cooptação 
das lideranças camponesas, acabou por exaurir o solo e criar barreiras técnicas nessas pequenas frações de terra. A região do ocidente boliviano viu uma grande Marcha hacia el Oriente (CIRELLI, 2014, p. 399), em que grandes comunidades indígenas migraram para as cidades do Altiplano ou para as terras baixas do oriente e acabaram por se submeter à lógica de assalariamento capitalista.

O processo de reforma agrária ocorreu em outro sentido no oriente (Santa Cruz de la Sierra), em que a terra era abundante e fértil e as formas de trabalho forçado vigoraram sobre as pequenas parcelas indígenas que viviam na região cruceña. Ligada ao polo agroexportador boliviano durante e após a $2^{\mathrm{a}}$ guerra mundial, a região recebeu maiores incentivos comparada com o ocidente mais densamente ocupado, resultando em fortes empresas agrícolas que, fruto de uma decisão política do governo MNR e seus sucessores (CIRELLI, 2014, p. 401).

\section{Considerações Finais}

Com o seu desenvolvimento econômico e político inserido dentro dos marcos da dependência, a Bolívia conta com a singularidade de seu povo para dinamizar sua história e lutar pela terra. Do vasto Tawantinsuyo e sua forma de cosmovivência com o território aos povos indígenas proletarizados e ligados com o sindicalismo da modernidade capitalista, a alteração da propriedade e da forma de produção revoluciona e transforma a sociabilidade em seu conjunto.

A generalização das formas sociais capitalistas e suas normas jurídicas de propriedade causaram dois fenômenos que tentamos expressar no decorrer do texto: a expropriação indígena de suas terras e a perda de territórios e fronteiras. Em um sentido, uma desorganização interna da produção, dada a incapacidade de substituir a forma comunal de produção por uma forma de rendimentos superiores para os expropriados, dentro dos marcos do capitalismo. Em outro, pela consequência da falta de dinamismo e busca por maiores lucros, as elites bolivianas se voltam para fora, por mercados e recursos, disputando com demais Estados o direito aos territórios em uma dinâmica predatória.

Dada a estrutura sociopolítica repressiva nas suas formas de produção e relações sociais, as ameaças de rupturas, ora revolucionárias, ora conservadoras, se tornam recorrentes. A Revolução de 1952 foi um desses momentos, contudo sintetizou uma nova realidade também contraditória em suas capacidades e objetivos. Ao ser capturada pelo Estado e incorporada com seus dispositivos burocráticos para manter a forma-mercadoria, $\mathrm{o}$ pilar da reforma agrária entrou dentro da lógica de mercado com seus minifúndios e suas empresas agrícolas, deformando a estrutura de produção na terra e dividindo socialmente ocidente e oriente boliviano.

\section{Referências}

ANDERSON, K. B. Marx nas margens: nacionalismo, etnia e sociedades não ocidentais. São Paulo: Boitempo, 2019.

ANDRADE, E. de O. A Revolução Boliviana. São Paulo: Editora UNESP, 2007.

BAMBIRRA, V. O capitalismo dependente latino-americano. Florianópolis: Insular, 2015.

BOLÍVIA. Vicepresidencia del Estado Plurinacional. Presidencia de La Asamblea Legislativa Plurinacional. La Paz, Bolívia. Disponível em: https://www.vicepresidencia.gob.bo/. Acesso em: 18 maio 2021.

CIRELLI, C. E. Antecedentes de un conflicto: La reforma agraria boliviana de 1953 y la profundización de las desigualdades entre oriente y occidente. Revista Cambios y Permanencias, Bucaramanga, n. 5, p. 387-410, dez./2014.

CUEVA, A. El desarrollo del capitalismo en América Latina y la cuestión del Estado. Problemas del Desarrollo. Revista Latinoamericana de Economía, v. 11, n. 42, p. 29-42, maio/2013.

CUSICANQUI, R. Apuntes para una historia de las luchas campesinas en Bolivia (1900-1978). In: CASANOVA, P. G. (org.). Historia política de los campesinos latinoamericanos. México: Siglo XXI, 1985. v. 3, p. 146-207.

FONTES, V. O Brasil e o capital imperialismo: teoria e história. Rio de Janeiro: EPSJV/Editora UFRJ, 2010.

KLEIN, H. S. História da Bolívia. Brasília: Universidade de Brasília, 2016.

LINERA, Á. G. A potência plebeia: ação coletiva e identidades indígenas, operárias e populares na Bolívia. São Paulo: Boitempo, 2010.

LINERA, Á. G. Forma Valor y Forma Comunidad. La Paz: Muela del Diablo, 2009.

MARIÁTEGUI, J. C. Sete ensaios de interpretação da realidade peruana. São Paulo: Expressão Popular, 2010.

MARINI, R. M., TRASPADINI, R.; STEDILE, J. P. (org.). Ruy Mauro Marini: vida e obra. São Paulo: Expressão Popular, 2011. 
MARX, K. Grundrisse: manuscritos econômicos de 1857-1858: esboços da crítica da economia política. São Paulo: Boitempo, 2011. MARX, K. O Capital: crítica da economia política: Livro I: O processo de produção do capital. 2a ed. São Paulo: Boitempo, 2017.

PLATT, T. Estado boliviano y ayllu andino: tierra y tributo en norte de potosí. La Paz: Biblioteca del Bicentenario de Bolivia, 2016.

RAMOS, J. A. História da Nação Latino-americana. Florianópolis: Insular, 2014.

RIBEIRO, D. O dilema da América Latina: estruturas de poder e forças insurgentes. Petrópolis: Vozes, 1978.

ROSTWOROWSKI, M. Historia del Tahuantinsuyu. Lima. Perú: Instituto de Estudios Peruanos, 1999.

SAAVEDRA, B. El Ayllu: Estudios sociologicos. La Paz: Librería Editorial “juventud”, 1998.

SOUZA, C. L. S. de. Racismo e luta de classes na América Latina: as veias abertas do capitalismo dependente. São Paulo: Hucitec, 2020.

\section{Notas}

1 Comunidades indígenas andinas de origem pré-incaica que perduram até os dias de hoje. Daremos mais atenção a este modelo comunitário posteriormente.

2 Autoridade paternal familiar dos ayllu.

3 A Quarta Internacional foi uma articulação de León Trotsky e seus seguidores, durante a Segunda Guerra Mundial, para fazer frente à hegemonia política de Joseph Stálin sobre os Partidos Comunistas ao redor do mundo.

4 Victor Aramayo, Mauricio Hochschild e Simón Patiño eram os três magnatas bolivianos, donos de mineradoras que estavam entre os homens mais ricos do início do século XX e que controlavam a política boliviana.

5 Campesinato médio de pequena propriedade que rivalizava com os grandes proprietários no abastecimento das regiões mineiras, vulnerável às mudanças econômicas e suscetível às influências proletárias.

6 Uma comunidade que reivindicasse uma porção de terra deveria ir à Junta Rural realizar uma audiência com proprietários e homens do governo, depois ir ao Juizado Agrário, a uma Chefatura Departamental da Reforma Agrária, ao Conselho Nacional de Reforma Agrária e, por fim, ao Ministério de Assuntos Camponeses (se chegasse até lá).

\section{Davi Antunes da Luz}

antunnesdavi@gmail.com

Bacharel em Relações Internacionais pela Universidade Federal de Santa Catarina (UFSC)

Mestrando no Programa de Pós-Graduação em Serviço Social pela Universidade Federal de Santa Catarina (UFSC)

\section{Lucas Lima da Silva}

limalucasbr@gmail.com

Graduando em Relações Internacionais pela Universidade Federal de Santa Catarina (UFSC)

\section{UFSC}

Campus Universitário Reitor João David Ferreira Lima - Trindade

Florianópolis - Santa Catarina - Brasil

CEP: $88.040-900$

\author{
Agência financiadora \\ Não se aplica. \\ Contribuições das autoras \\ $\mathrm{O}$ artigo foi elaborado em todas as partes pelos autores. \\ Aprovação por Comitê de Ética \\ Não se aplica.
}

\section{Consentimento para publicação}

Consentimento dos autores.

Conflito de interesses

Não há conflito de interesses. 